\title{
Analysis of Regional Industrial Specialization Difference in China \& Decomposition Approaches Based on Regression Function: A Case Study of Guangdong Province
}

\author{
Jingzhang Liu, Yelan Wu \\ Jinan University, Guangdong, China \\ Email: 1606686243@qq.com
}

How to cite this paper: Liu, J.Z. and $\mathrm{Wu}$, Y.L. (2017) Analysis of Regional Industrial Specialization Difference in China \& Decomposition Approaches Based on Regression Function: A Case Study of Guangdong Province. Modern Economy, 8, 25-38. http://dx.doi.org/10.4236/me.2017.81003

Received: December 16, 2016

Accepted: January 8, 2017

Published: January 11, 2017

Copyright ( 92017 by authors and Scientific Research Publishing Inc. This work is licensed under the Creative Commons Attribution International License (CC BY 4.0).

http://creativecommons.org/licenses/by/4.0/

(c) (i) Open Access

\begin{abstract}
This paper used the dynamic panel data from 2004 to 2013 of 21 municipalities in Guangdong Province to study the tendency and the influence factors of regional industrial specialization. We found that in the sample period, the difference of regional industrial specialization showed staged change, however, it kept an uptrend overall. Based on the inequality decomposition of regression equation, we found that the regional original industry specialization was the most important factor of regional industry specialization difference, followed by market potential, wage level, total factor productivity, capital shock, opening degree, reform progress and transport infrastructure. This empirical result indicated the direction of the industrial structure transformation and industry policies formulation in Guangdong Province.
\end{abstract}

\section{Keywords}

Dynamic Panel, Regional Industrial Specialization, Regional Difference, Decomposition of Inequality

\section{Introduction}

China's economy has entered into the new normal of medium-high-level growth, and innovation will be the key driver for future development. What's the new normal? Firstly, it is a new concept beyond GDP growth and attaches importance to the quality of economic growth and development; secondly, it establishes a new policy thinking and tone, it no longer tangles for speed and stands on long-term development; thirdly, it is not a pessimistic attitude but a confident attitude facing all kinds of challenges. According to the general rules 
of national economic development, it is possible to assign a fact that the industrialization drive of China is almost over; the transformation and innovation have become the themes of the new normal. The industrial upgrading is closely related with the industrial specialization, it is known that the industrial upgrading is not only the vital elements of industrial restructuring but also an eternal theme in economic development. The industrial upgrading means that the factors of production focuses on configuring the certain industries in a certain district, that is, a few industries make important contributions to the gross annual value of the local economy. The industrial specialization is a sign of resource optimization allotment, which has become economical problem all over the world. Regional industrial specialization is an effective way to improve regional industrial competitiveness. Industries with comparative advantages tend to concentrate on particular regions, thus, industrial agglomeration promotes economic growth.

The studies about the industrial specialization are no lack of minority. However, most give attention to the impact of regional industrial specialization. For example, based on the perspectives of external MAR, Jacobs external and Poter external, study whether the industrial specialization or diversification is more helpful to economic growth, regional employment growth and stability, urbanization and regional industrial innovation (see, e.g. [1]-[7]). The research perspectives may be different; however, all of them stress the importance of industry specialization. In comparison, the studies concerning on what are the influence factors of the industry specialization differences, which is the most important in the influence factors and how to use the policy guidance to promote the development of the regional industrial specialization are relatively rare. Apart from this, according to measuring the regional industrial specialization of different provinces in China, Zhang and Wen Cheng [8] found that the original regional industrial specialization, wage level, transportation infrastructure, foreign trade and foreign direct investment were the influence factors of disequilibrium among the regional industrial specialization in turn. However, the subject in the study is the province (provinces are different each other) only through the Gini coefficient of regional industrial specialization differences concluded that there may be some bias. As we know, China has entered into new normal, need readjust and optimize industrial structures. The optimization and upgrading of industrial structure are a dynamic process in an economic system, which is inextricably tied up with industrial specialization. The influence factors of the industry specialization differences maybe the obstacles of the optimizing and upgrading industrial structures, then this paper tries to fill research vacancy in Industrial specialization inequality. This paper made contributions in the three aspects as follows: firstly, the paper applied different inequality indexes including Gini coefficient and Generalized Entropy Index $\left(\mathrm{GE}_{0}, \mathrm{GE}_{1}\right)$ to measure the evolution trend of differences in the regional industrial specialization of the 21 municipalities in Guangdong Province; secondly, this paper used the Shapley value to decompose the influencing factors of the regional industrial specialization differ- 
ences to ensure the contribution fractions of the influencing factors to the regional industrial specialization differences; thirdly we put forward the relative policy recommendations according to the quantitative analysis.

The Second Part discussed the sources of data and described the unequal tendency of the 21 municipalities in Guangdong Province. The Third Part built the regression model of the regional industrial specialization and conducted the decomposition of inequality. The Forth Part is a summary of the full text, and put forward some relevant proposals.

\section{Literature Review}

According to the available literature, there are many indicators to measure the regional industrial specialization, for example the Gini coefficient, HHI index, Location Entropy and so on. If you only want to measure the level of industrial specialization to determine whether it is more focused on the development of certain industries rather than compared with other regions or the whole country. In general, we use the Gini coefficient frequently; it means to measure the distribution of the industrial share of a region [9]. The Gene coefficient was originally used to study the inequality of income distribution. Later it's widely used to measure the inequality between other variables. Recently, it was widely used to calculate the degree of industrial agglomeration [10] [11]. Now we try to use it to measure the level of regional industrial specialization in a certain region, which is designated as the Local specialization Gini coefficient, the data which are the absolute data not the relative indices are from the sectoral distribution of employment in a certain region. The value ranges from 0 to 1 , the bigger this value is the higher the regional industrial specialization, and vice versa. We adopted the Gini coefficient formulas of discrete distribution, which is defined by A. Sen.

$$
\text { Spec }=\frac{2}{n}\left[\sum_{i=1}^{n} i x_{i}\right]-\frac{(n+1)}{n}
$$

$x_{1}$ represents the quantity of employment in the industry of a certain region, which is stored in ascending order in accordance with $x_{1} ; x_{2} ; \cdots ; x_{n-1} ; x_{n}$. $n$ means sample size. $i$ represents the A-P, a total 19 single digit industry in addition to $\mathrm{T}$ in the National Economical Industry Classification.

The most frequently used inequality indexes including the Generalized Entropy Index $\left(\mathrm{GE}_{0}\right.$ and $\left.\mathrm{GE}_{1}\right)$; the Atkinson index; the Gini coefficient and the square of variation coefficient. There is a monotonic transformation relationship between the Atkinson index and the Generalized Entropy Index [12], so they are equivalent to each other. The variance coefficient squared is contrary to the transfer of principle of the inequality indexes. Because the Gini coefficient is more sensitive to the change of the middle level, instead, the Theil index is more sensitive to the Upper, $\mathrm{GE}_{0}$ and $\mathrm{GE}_{1}$ were more sensitive to the bottom [13] for the sake of measuring the difference of Regional industrial specialization more comprehensively.

As shown in Figure 1: the difference of regional industrial specialization in Guangdong appeared staged tendency; however, the overall showed an uptrend 


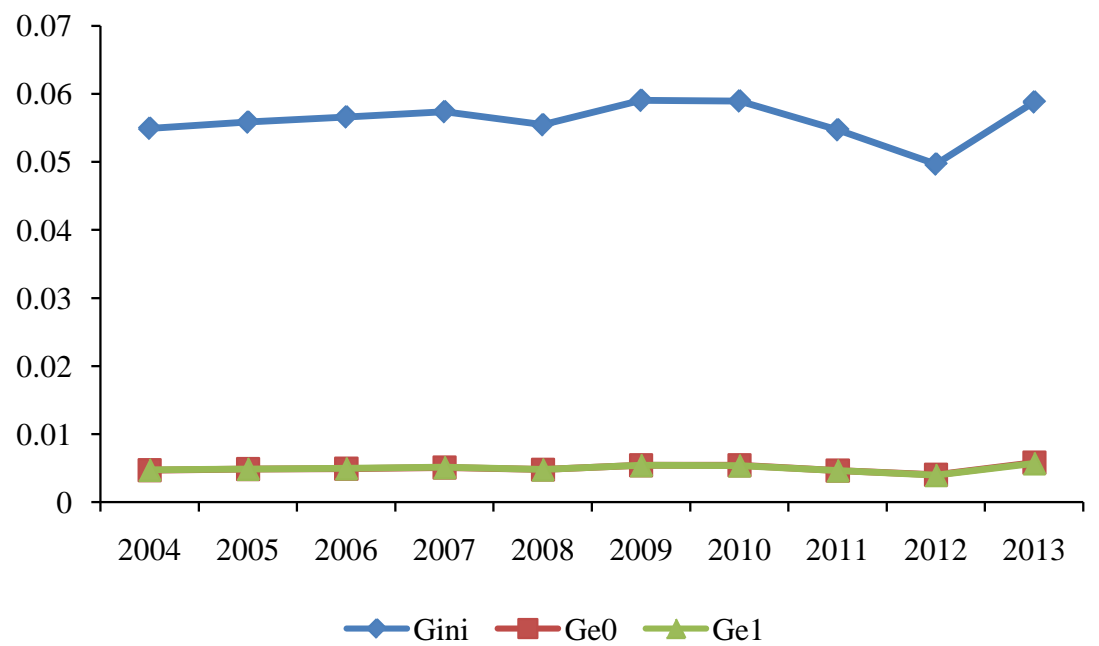

Figure 1. 2004-2013, the tendency of the difference of Regional industrial specialization in the 21 municipalities in Guangdong Province.

from 2004 to 2013, three regional difference indexes gave us a same tendency generally. It indicated that all three had a good consistency during measuring the difference of regional industrial specialization. Among them the Gini coefficient fluctuated greater.

\section{Research Methods and Variables Selection}

According to the existing literature and the availability of comprehensive data, the article chose the original industrial specialization; wage level; capital stock; open degree; reform progress; market potential; total factor productivity; transport infrastructure to explain the difference of regional industrial specialization. The data of the paper all originated from the China City Statistical Yearbook unless otherwise stated. In the China City Statistical Year Book, cities consist of the municipal districts and the county, nevertheless, the numbers of the city counties are changing in time, and the numbers of the municipal districts are relatively stable. Accordingly, this paper adopted the data of the municipal districts.

When conducting this empirical study, in order to eliminate the heteroscedasticity from the source, we used log form to denote every variable. The dynamic panel model is as follows:

$$
\begin{aligned}
\ln \text { Spec }_{i t} & =\beta_{1} \ln \text { Spec }_{i t-1}+\beta_{2} \ln t f p_{i t}+\beta_{3} \ln \text { wage }_{i t}+\beta_{4} \ln \text { market }_{i t}+\beta_{5} \ln k_{i t} \\
& +\beta_{6} \ln \text { road }_{i t}+\beta_{7} \ln \text { reform }_{i t}+\beta_{8} \ln \text { open }_{i t}+u_{i}+v_{i t}
\end{aligned}
$$

$i$ denotes the the 21 municipalities in Guangdong Province, $i=1,2, \ldots, 21 ; t$ stands for the time, $t=2004, \ldots, 2013 ; u_{i}$ represents individual differences of every city which is unable to be observed; $v_{i t}$ indicates stochastic error; $\beta_{1}, \beta_{2}$, $\beta_{3}, \beta_{4}, \beta_{5}, \beta_{6}, \beta_{7}$ and $\beta_{8}$ indicated the influence coefficient of the original industrial specialization; total factor productivity; wage level; market potential; capital stock; transport infrastructure; open degree; reform progress to the difference of 
the regional industrial specialization in turn. The definition and measurement of variables are below.

\subsection{First-Order plus Dead-Time of the Regional Industrial Specialization $\left(\right.$ Spec $\left._{t-1}\right)$}

The labor transfer possess viscosity, transformation and upgrading of industrial structure are a long and complicated process. So the regional industrial specialization has durability in time. The article adopted the first-order plus dead-time of the regional industrial specialization $\left(\operatorname{Spec}_{t-1}\right)$ as explanatory variable joining the model. The article used the regional industrial specialization from 2003 to 2013 in the 21 municipalities in Guangdong Province as the first order plus time delay; therefore, we forecasted the $\beta_{1}$ between zero and one.

\subsection{Total Factor Productivity ( $t f p$ )}

The majority of domestic and foreign scholars' empirical research arrived at a consensus that there is mutually promotional relationship between the total factor productivity, industrial agglomeration and industrial specialization. Lucio et al. [14] found that the industrial specialization was conducive to improving labor productivity and the technology spillover effect on agglomeration effect is obvious, according to taking advantage of twenty-six industry data of Spain from 1978 to 1992. In this paper, DEA method was used to calculate the total factor productivity by using the Malmquist index model. The capital stock and the labor stock specified as inputs, different levels in Guangdong Province of the investment in fixed assets were a substitute for the capital stock index. The employment of prefectural-level cities in Guangdong at the end of every year measured in terms of the labor variables. The local GDP and the average annual salary of an urban employee specified as outputs. The improvement of total factor productivity was stimulated by technological progress, for that reason, enterprises can offer more products, which is unfavorable to the development of the regional industrial specialization, therefore, we speculated the $\beta_{2}$, which was less than zero.

\subsection{Wage Level (wage)}

According to the two regions model of Krugman, if there are many such enterprises in a region, consumers as workers will be able to buy the goods at a lower cost. The local has witnessed a lower consumer price index and real wages are higher, which means workers also tend to choose to live and work in the area and enterprises gather together further. This paper used average wage of every city standing for the wage levels of a region, the higher the wage was, the more willing to choosing working and living in this area the workers were, which is conducive to industry clusters. Therefore, we expected the $\beta_{3}$ between 0 and 1 in this paper.

\subsection{Market Potential (market)}

The concept of market potential was first proposed by the Clark, it was a mea- 
surement of the possibility of the city proximity to the market, which reflected the overall market scale of a city, According to using the market potential function to portray the advantages of different areas of American close to the market, Harris (1954) found that the bigger the market potential of metropolises in American was, the faster the industry expanded. The increasing Market potential spurred the company to make excess profit, and attracted more enterprises to enter. With the increase of the business registrations, there will be a variety of differentiated products in the market; hence this paper forecasted the $\beta_{4}$ below 0 .

Different scholars put forward different calculation methods on the measurement of Market potential. The market potential function put forward by Harries [15] and Ma; Sa index put forward by Redding, Venables [16] were the most common. Based on the availability of data, this paper adopted market potential function put forward by Harries [15], the calculation formula was as follows:

$$
m p_{i}=\sum_{j \neq i} \mathrm{GDP}_{j} / d_{i j}+\mathrm{GDP}_{i} / d_{i}
$$

GDP was the gross domestic product of every city; $d_{i j}$ stood for center distance between two cities. This paper used the data of the distance between administrative center of $i$ and administrative center of $j$ which got through the Arcview3.3 Software; $d_{i}$ represented the inner distance of $i$. The paper based on the evaluating formula proposed by Xiuyan, Liu, et al. [17]. $d_{i}=\frac{2}{3} \sqrt{\frac{s_{i}}{\pi}}, s_{i}$ is the administrative area of a city.

\subsection{Capital Shock $(k)$}

Capital stock is an important economic source of enterprise investment and the major influencing factor of the economic growth according to the classical theory about economic growth, especially in the phase of industrialization. Investment in fixed assets in each city was demonstrated the capital shock of the region. With the increase of capital shock, entrepreneurs preferred diversifying into other areas; hence the $\beta_{5}$ is below 0 .

\subsection{Transport Infrastructure (road)}

Transportation cost; economies of scale and the share of manufacturing in the economy were the three influencing factors of the industry specialization in the core-peripherymodel of Krugman. Lower transportation cost; bigger economies of scale and higher share of manufacturing in the economy were the sustainability conditions of the industry specialization. Transportation infrastructure development was an indispensable variable of measuring the city investment environment. Transport infrastructure had spatial spillover effects, which was a critical factor when the government initiated policies [18], on the basis of existing data. Per area of the urban roads expressed the traffic accessibility and the transportation condition in this paper [5] [19]. The improvement of the traffic infrastructure can lower transaction costs; therefore, we forecasted the $\beta_{6}$ between 0 and 1. 


\subsection{Reform Progress and Opening Degree (reform and open)}

Traditional economists thought that the trade was the driving force of the national industrial specialization, which spurred the nation into specialization in a certain Industry. Xinfei Huang and Yuan Shu [20] found that opening degreerose total factor productivity, exhibited economies of scale, optimized the distribution of resources and quickened the pace of technical advancement, which induced a nation to produce comparative advantage industry. Reform and opening up as the Chinese characteristics strengthened the links between all parts of the country and promoted economic growth. Guangdong, as the forward position of reform and opening-up of our country, whose urban development and industrial relocation were the forefront of development, whose industrial development direction and structure adjustment were severely affected by the reform and opening. This paper applied the employment non-state-owned economy of the total employment proportion to estimating the progress toward reforming, used the ratio of the FDI and the total Export-Import volume to the GDP as the index of the regional openness. Reform and opening as the social infrastructure can lower transaction costs, so this paper deduced the $\beta_{7}$ and $\beta_{8}$ all between 0 and 1 .

\section{Empirical Analysis}

This paper adopted the method of sharply value to decompose the influencing factors of the regional industrial specialization difference. For the sake of inequality decomposition, $t$ his paper used the stata13.0 to solve the regression equation. This model involved the first-order plus dead-time of explanatory variables, which caused the explanatory variables correlated with the random disturbances. If it applied the Fixed Effects (FE) and Random Effects (RE) to estimating, the result may be biased, we considered the endogeneity of key variables in our regression models and adopted IV approach and GMM method to resolve the problem of endogeneity. And then we got more credible results. However, it was difficult to select appropriate instrumental variables, which affected the robustness of model. The panel GMM estimation overcomes the shortcomings of the OLS, fixed effects analysis, and avoided endogenous model. In addition, panel GMM method included difference GMM (DIF-GMM) and System GMM (SYS-GMM) Estimation. The estimators of DIF-GMM whose features of the limited samples were uncoordinated, especially when the first-order difference was weakly correlated with the lagged dependent variable; the effect of the IV will be weak [21]. Whereas System GMM method combined difference GMM and level GMM, whose advantages were to improve the validity of estimation [22]. For that reason, we adopted System GMM method. Because endogenous regression coefficient hided bias, we used Sargan Statistics to test the effectiveness of IV selected. If we accept a null hypothesis, which meant that the selected IV were valid. On the basis of AR (1) and AR (2), judge whether the residuals are the serial correlation. The estimation results listed in Table 1.

On the basis of the regression results, the impacts of explanatory variables 
Table 1. The regression results between the regional industrial specialization and the influence factors.

\begin{tabular}{|c|c|}
\hline Explanatory variables & Explained variable $(\ln S p e c)$ \\
\hline $\ln S p e c$ & $\begin{array}{l}0.402^{* * *} \\
(3.54)\end{array}$ \\
\hline $\ln r o a d$ & $\begin{array}{c}0.020^{* *} \\
(2.2)\end{array}$ \\
\hline $\ln t f p$ & $\begin{array}{c}-0.062^{* * *} \\
(-3.26)\end{array}$ \\
\hline lnwage & $\begin{array}{c}0.096^{* * *} \\
(3.60)\end{array}$ \\
\hline lnopen & $\begin{array}{l}0.004^{* * *} \\
(2.72)\end{array}$ \\
\hline $\ln r e f o r m$ & $\begin{array}{l}0.073^{* *} \\
(2.07)\end{array}$ \\
\hline $\ln k$ & $\begin{array}{l}-0.053^{* *} \\
(-2.25)\end{array}$ \\
\hline lnmarket & $\begin{array}{c}-0.050^{* *} \\
(2.07)\end{array}$ \\
\hline _cons & $\begin{array}{l}0.087 \\
(0.79)\end{array}$ \\
\hline Abond test $\mathrm{AR}(1)$ & $\begin{array}{c}-0.42291 \\
{[0.6742]}\end{array}$ \\
\hline Abond test $\operatorname{AR}(2)$ & $\begin{array}{c}-0.38124 \\
{[0.7030]}\end{array}$ \\
\hline Sargan test & $\begin{array}{c}7.0362 \\
{[0.9726]}\end{array}$ \\
\hline
\end{tabular}

Note: ${ }^{* *},{ }^{* *},{ }^{*}$ represent the $1 \%, 5 \%$ and $10 \%$ significance level, $t$ values in parentheses. All of the regression models were two steps.

which were considered in the model on the regional industrial specialization were significant. The original regional industrial specialization; wage level; transport infrastructure; opening degree and reform progress had obvious positive effect on the regional industrial specialization. On the contrary, Total factor productivity; capital stock and market potential had negative influence on the regional industrial specialization, which meant the degree of the regional industrial specialization decreased with the increase of the three factors.

The decomposition method of Shapley Value was put forward by Shorrocks (1999) [23], which were mainly applied in income distribution area. Whereas, this method was widely used in the determinants of innovation capability asymmetry [24]; the analysis of Influencing factor and differences of insurance Industry development among different regions in China [25]; the reason of income inequality in the manufacturing industry [26]; the health inequality of aging people in the countryside [27] and so on. So this paper adopted this method to deeply decompose the difference of the regional industrial specialization. The 
regression equation was combined with the decomposition principle of Shapley Value [28], which can be calculated the degree of inequality which was the impacts of the explanatory variables on the explained variables in a unified analysis framework. the main idea of this method was as follows: a independent variable (for example $\mathrm{X}$ ) in the function of the regional industrial specialization took sample mean, then put the average values of $\mathrm{X}$ and actual values of other variables into the determining equations of the regional industrial specialization, speculate the data of the regional industrial specialization and calculate inequality indices corresponding to the difference of industrial specialization, written I so that I did not contain the impact of the X. The difference between I and (I) which was calculated the difference of the regional industrial specialization based on the real data was the contribution of $\mathrm{X}$ to the regional industrial specialization. If $\mathrm{X}$ took the mean, the difference of the regional industrial specialization narrowed, which meant that $\mathrm{X}$ amplified the difference of the regional industrial specialization, in other words, the $\mathrm{X}$ of contribution to regional industrial specialization was positive or contrary. We can infer that it speculated the regional industrial specialization difference of the $\mathrm{X}$ mean basing on the function deciding regional industrial specialization, the value of each variable is not unique, which may be actual value or mean value.

On the basis of the regression results in Table 1, we used the fitted value of model to calculate the Gini coefficient of the regional industrial specialization difference and got the impact of the residual on the regional industrial specialization difference. The contribution of the residual can be explained as influence factors of the regional industrial specialization difference, which were not considered in the model. Ideally, the influence of the residual is zero, however, it's usually not zero, and we can judge the explanatory power of the regression results to the regional industrial specialization difference. In Table 2, we used the ratio which is the impact of the residual on the regional industrial specialization difference as the influencing factors of the regional industrial specialization difference not considered in the model, 1 less the ratio equals the degree of explaining extent of all independent variables in the model to the regional industrial specialization difference. According to this principle, the degree of explaining extent of all independent variables in the model kept above $97 \%$, that is, the regression model had very strong explanation strength.

Based on the decomposition results in Table 3, the regional original industry was top contributor to the regional industry specialization difference among all

Table 2. Gini coefficient of regional industrial specialization difference and the explanation strength of the model.

\begin{tabular}{ccccccccccc}
\hline Year & 2004 & 2005 & 2006 & 2007 & 2008 & 2009 & 2010 & 2011 & 2012 & 2013 \\
\hline $\begin{array}{c}\text { Explaining degree of } \\
\text { residual (\%) } \\
\begin{array}{c}\text { Explanation strength of } \\
\text { model (\%) }\end{array}\end{array}$ & 1.00 & 1.53 & 1.51 & 1.54 & 1.24 & 1.84 & 1.48 & 1.03 & 1.83 & 2.41 \\
\hline
\end{tabular}


Table 3. The influence factors of the regional industry specialization difference decompose from 2004 to 2013.

\begin{tabular}{|c|c|c|c|c|c|c|c|c|c|c|c|c|c|c|c|c|}
\hline \multirow{2}{*}{$\begin{array}{c}\text { Factors } \\
\text { Year }\end{array}$} & \multicolumn{2}{|c|}{$\begin{array}{c}\text { Original } \\
\text { region } \\
\text { industrial } \\
\text { specialization }\end{array}$} & \multicolumn{2}{|c|}{$\begin{array}{c}\text { Market } \\
\text { potential }\end{array}$} & \multicolumn{2}{|c|}{ Wage level } & \multicolumn{2}{|c|}{$\begin{array}{l}\text { Total factor } \\
\text { productivity }\end{array}$} & \multicolumn{2}{|c|}{ Capital shock } & \multicolumn{2}{|c|}{ Open degree } & \multicolumn{2}{|c|}{$\begin{array}{l}\text { Reform } \\
\text { progress }\end{array}$} & \multicolumn{2}{|c|}{$\begin{array}{c}\text { Transport } \\
\text { infrastructure }\end{array}$} \\
\hline & SC & ACR & SC & ACR & SC & ACR & SC & ACR & SC & ACR & SC & ACR & SC & ACR & SC & ACR \\
\hline 2004 & $1,1,1$ & 34.41 & $4,5,6$ & 6.39 & $2,2,2$ & 27.80 & $3,3,3$ & 22.84 & $6,8,8$ & -3.14 & $7,6,5$ & 3.34 & $5,4,4$ & 8.99 & $8,7,7$ & -0.64 \\
\hline 2005 & $1,1,1$ & 34.16 & $4,3,4$ & 16.92 & $2,2,2$ & 22.08 & $3,4,3$ & 16.22 & $5,5,5$ & 8.28 & $7,6,6$ & 2.30 & $6,8,7$ & 0.96 & $8,7,8$ & -0.92 \\
\hline 2006 & $1,1,1$ & 35.18 & $2,2,2$ & 21.85 & $3,4,4$ & 19.39 & $4,3,3$ & 13.20 & $5,5,5$ & 12.46 & $7,6,6$ & 1.81 & $6,8,8$ & -2.94 & $8,7,7$ & -2.14 \\
\hline 2007 & $1,1,1$ & 34.89 & $2,2,2$ & 24.22 & $4,4,4$ & 17.03 & $3,3,3$ & 19.73 & $5,5,5$ & 9.14 & $7,6,6$ & 1.44 & $6,8,8$ & -4.09 & $8,7,7$ & -2.35 \\
\hline 2008 & $1,1,1$ & 35.48 & $2,2,2$ & 23.13 & $4,4,4$ & 17.07 & $3,3,3$ & 19.45 & $5,5,5$ & 9.36 & $7,6,6$ & 1.47 & $6,8,8$ & -3.8 & $8,7,7$ & -2.17 \\
\hline 2009 & $1,1,1$ & 35.84 & $2,2,2$ & 22.04 & $4,3,4$ & 18.78 & $3,4,3$ & 19.61 & $5,5,5$ & 9.4 & $7,6,6$ & 1.33 & $6,8,8$ & -2.45 & $8,7,7$ & -1.90 \\
\hline 2010 & $1,1,1$ & 34.99 & $2,2,2$ & 21.67 & $4,3,4$ & 18.11 & $3,4,4$ & 16.82 & $5,5,5$ & 10 & $7,6,6$ & 1.44 & $6,8,8$ & -1.06 & $8,7,7$ & -1.97 \\
\hline 2011 & $1,1,1$ & 35.64 & $2,2,2$ & 23.32 & $4,3,3$ & 15.13 & $3,4,4$ & 14.88 & $5,5,5$ & 11.76 & $7,6,6$ & 1.28 & $6,8,7$ & -0.37 & $8,7,8$ & -1.64 \\
\hline 2012 & $1,1,1$ & 34.66 & $2,2,2$ & 25.74 & $4,3,3$ & 15.71 & $3,4,4$ & 13.67 & $5,5,5$ & 12.1 & $7,6,6$ & 1.13 & $6,8,8$ & -1.43 & $8,7,7$ & -1.58 \\
\hline 2013 & $1,1,1$ & 34.78 & $2,2,2$ & 24.00 & $4,3,4$ & 15.12 & $3,4,4$ & 15.32 & $5,5,5$ & 12.81 & $7,6,6$ & 1.53 & $6,8,8$ & -1.78 & $8,7,7$ & -1.78 \\
\hline 2004-2013 & 1 & 35.003 & 2 & 20.928 & 3 & 18.622 & 4 & 17.174 & 5 & 9.217 & 6 & 1.707 & 7 & -0.797 & 8 & -1.709 \\
\hline
\end{tabular}

Note: In Table 3, SC means the sorting of contribution rate, ACR represents the average rate of the contribution, and the contribution rates of influencing factors are calculated according to the software of WIDERdecOm20041126.

explanatory variables, whose contribution rate accounted for 35\% during all 10 years. Industrial structure adjustment to profession will be a long process, in order to narrow the degree of industrial specialization in different regions, efforts to restructure should be strengthened, especially in under-developed areas. This was followed closely by market potential, which accounted for $20.928 \%$. Efforts should be made to expand the market size and improve the accessibility of the market. The influence factor in third place was wage level, which accountedfor $18.622 \%$. The government should perfect the income distribution mechanism, enhance transfer payments to backward areas and increase wages so that the regional industry specialization difference can be reduced. The influence factor in fourth place was total factor productivity, which accounted for $17.174 \%$. Hence businesses should strengthen innovation investment and improve technical efficiency. The influence factor in fifth place was capital shock, which accounted for $9.217 \%$. The influence factor in sixth place was opening degree, which accounted for $1.707 \%$. Reform progress and transport infrastructure were of special among all influence factors, whose contributions to the regional industry specialization difference were negative, they respectively accounted for $-0.797 \%$ and $-1.709 \%$. Contribution rate was a minus; this is, with the reform progress and transport infrastructure improvement, the regional industry specialization difference narrowed. Reform progress and transport infrastructure generally helped the regional industry specialization difference to narrow during the sample period in all influence factors. 
The contribution was sorted by the importance of eight influence factors to the regional industry specialization difference, which was measured by the Gini coefficient, $\mathrm{GE}_{0}$ and $\mathrm{GE}_{1}$. The most important ranked first, the least important placed the eighth. In view of the tendency, the contribution to the regional industry specialization difference of the factors varied slightly during the sample period. The contribution of the original regional industry specialization to the regional industry specialization difference remained relatively stable, which approximately maintained $35 \%$. The contribution of the market potential and capital shock to the regional industry specialization difference had great variation during the sample period. However, they still continued the trend of increasing as a whole. The contribution of the market potential run at more than $25.74 \%$, the contribution of the capital shock rose gradually from $-3.14 \%$ to $12.81 \%$ in the sample period; this also showed that the contributions of other factors to the regional industry specialization difference declined. The contribution of wage level decreased gradually from $27.80 \%$ in 2004 to $15.12 \%$ in 2012; the contributions of the opening degree reached the minimum in 2012. The contributions of total factor productivity varied greatly in the individual years, whereas it kept a downtrend overall. The contributions of reform progress varied greatly during ten years, the contribution rate had a decline from 2004, recovered in 2008 and began to fall from 2011. During the sample period excepting the 2004 and 2005, the contribution of these influence factors remained broadly consistent, although there may be a replacement of the individual position, the contributions of the influence factors which were measured by the Gini coefficient, $\mathrm{GE}_{0}$ and $\mathrm{GE}_{1}$ were sorted basically the same. There were slight difference among the order of opening degree, reform progress and transport infrastructure. Maybe the influence factors selected were a little much so that the sorting of Individual indicators existed discrepancy, which had no influence on the analysis results. Because the impacts of the three factors on the regional industry specialization difference were slight. Three indicators describing regional industrial specialization differences were consistent in essence. So we adopted the gaging methods of regional industry specialization difference, which had strong robustness and reliability.

\section{Conclusions and Implications}

This paper co-opted the gaging methods of income inequality, we adopted different inequality indexes (Gini coefficient, $\mathrm{GE}_{0}$ and $\mathrm{GE}_{1}$ ) to measure the difference and tendency of regional industry specialization. We found that the difference of the regional industry specialization in 21 municipalities in Guangdong Province showed staged tendency, whereas it kept a rising trend slowly. Based on the decomposition method of Shapley Value, we found that the important factors deciding the regional industry specialization were in turn: original regional industry specialization, market potential, wage level, total factor productivity, capital shock, opening degree, reform progress and transport infrastructure. Opening degree and transport infrastructure were helpful to reduce the difference of the regional industry specialization. 
Several policy implications were derived from the findings: firstly, because different regions of industry specialization had their own characteristics of tendency, industrial restructuring of different regions should adjust measures not only to local conditions but also to specified periods. Secondly, the regional industry specialization had become the inevitable trend of economy development, when the government devised industrial policy which should attach importance to the development of the industrial structure, strength preferential policies of industry specialization. Thirdly, market potential was the second factor of regional industry specialization difference, so it should make efforts to enlarge the market capacity, improve infrastructure and market accessibility. Fourthly, the issue of income distribution had drawn more and more attention, if we reduced wage gap of workers and adjusted the industrial structures to the direction of specialization, which could kill two birds with one stone. Fifthly, relatively backward areas should further intensify reform efforts, besides, the government provided more favorable export-and-import policies for attracting business and investment, and only in this way can we effectively narrow regional differences and promote industrial adjustment and optimization.

\section{Acknowledgements}

Many people have made invaluable contributions, both directly and indirectly to our research. I would like to express my warmest gratitude to them. We thank the editor and anonymous referees for their instructive suggestions and valuable comments on the writing of this thesis. And we thank the professor in Jinan University; without their help, the present thesis would not have been accomplished. Finally, we greatly appreciate all the people who helped us.

\section{References}

[1] Henderson, V. (1997) Externalities and Industrial Development. Journal of Urban Economics, 42, 449-470. https://doi.org/10.1006/juec.1997.2036

[2] Jiang, Y.Y. (2011) Empirically Studies on Regional Specialization in China Boosting Economic Growth from 1990 to 2007. The Journal of Quantitative \& Technical Economics, 1, 3-20.

[3] Su, H.J. and Zhao, J. (2011) The Studies of Industrial Specialization, Function Specialization and Economic Growth \& Panel Data Based on Chinese Prefecture-Level City. China Industrial Economy, 4, 25-34.

[4] Sun, X.D., Zhang, L.L. and Zhao, Z. (2016) The Source of Urban Agglomeration Economy: Specialization or Diversification. Finance Economics, 2, 113-122.

[5] Li, J.Y. and Song, D.Y. (2008) Empirically Studies of Specialization, Diversification and Urban Agglomerative Economies \& Panel Data Based on Chinese PrefectureLevel City. Management World, 1, 25-34.

[6] Yao, D.W. and Sun, G.F. (2016) The Impacts of Industrial Specialization on Urbanization \& Panel Data Based on the Yangtze River Delta from 1986 to 2012. Journal of Shanxi Finance and Economics University, 2, 61-76.

[7] Shi, P. and Zheng, J.H. (2010) The Changes of Innovation and Industry Specialization \& a Case Study of Jiangsu Province. Industrial Economics Research, 6, 43-49.

[8] Zhang, J.H. and Cheng, W. (2012) The Evolution Regional Industrial Specialization 
in China Showed "U” Type Track Model. Social Sciences in China, 1, 76-99.

[9] Aiginger, K. and Leitner, W. (2002) Regional Concentration in the United States and Europe: Who Follows Whom? Review of World Economics, 138, 652-679. https://doi.org/10.1007/bf02707656

[10] Ge, Y. (2004) Industrial Agglomeration and Foreign Trade. The Discussion Paper of the Forth Economics Annual Meeting, Tianjin, 35-47.

[11] Liang, Q. (2004) Industry Agglomeration Theory. Commercial Press, Beijing.

[12] Shorrocks, A. and Slottje, D. (2002) Approximating Unanimity Orderings: An Application to Lorenz Dominance. Journal of Economics, 9, 91-118.

https://doi.org/10.1007/BF03052501

[13] Wan, G. (2004) Income Inequality of Rural Districts in China \& Decomposition Approaches Based on Regression Function. Economic Research Journal, No. 8, 117127.

[14] De Lucio, J.A. and Goicolea, A. (2002) The Effects of Externalities on Productivity Growth in Spanish Industry. Regional Science and Urban Economic, 32, 241-258. https://doi.org/10.1016/S0166-0462(01)00081-3

[15] Harris, C. (1954) The Market as a Factor in the Localization of Industry in the United States. Annals of Association of American Geographers, 44, 315-348. https://doi.org/10.1080/00045605409352140

[16] Redding, S. and Venables, A. (2004) Economic Geography and International Inequality. Journal of International Economics, 62, 53-82. https://doi.org/10.1016/j.jinteco.2003.07.001

[17] Liu, X., He, X. and Yin, X. (2007) Empirically Studies of Market Potential and Regional Wage Gap \& Panel Data Based on Chinese Prefecture-Level City. Management World, No. 9, 48-55.

[18] Ding, H. (2016) Infrastructure Development of Yangtze Economic Zone and the Space Characteristics of the Economic Growth. Statistics \& Information Tribune, No. 1, 24-32.

[19] Jin, Y., Chen, Z. and Ming, L. (2006) Industry Agglomeration in China: Economic Geography, New Economic Geography and Policy. Economic Research Journal, No. 4, 79-89.

[20] Huang, X. and Shu, Y. (2007) The Studies on the Trade Openness, Industrial Specialization and Economic Growth in China. Journal of International Trade, No. 12, 11-17.

[21] Roodam, D. (2009) How to Do Xtabond2: An Introduction to Difference and System GMM in Stata. The Stata Journal, 9, 86-136.

[22] Chen, Q. (2014) Advanced Econometrics and Applition of Stata. Higher Education Press, Beijing.

[23] Shorrocks, A.F. (1999) Decomposition Procedures for Distributional Analysis: A Unified Framework Based on the Shapley Value. Department of Economics, University of Essex, Essex.

[24] Wan, G., Fan, B. and Lu, M. (2010) Analysis of Innovation Inequality in China \& Decomposition Approaches Based on Regression Function. The Journal of World Economy, No. 2, 3-14.

[25] Wu, H. and Zhao, G. (2011) The Changes of Regional Development Discrepancy in Insurance Industry and Explanations \& Decomposition Approaches Based on the Sharply Value. Insurance Studies, No. 10, 14-21.

[26] Yan, B., Xuan, G. and Han, J. (2014) Reasons Decomposition and Change Trend of 
Income Inequality in Manufacturing Industry. The Journal of World Economy, No. 12, 27-46.

[27] Tan, T., Zhang, Q. and Liu, H. (2015) Health Inequality of the Elderly in Rural China and Decomposition \& Empirical Research Based on China's East and West. South China Population, No. 3, 57-68.

[28] Wan, G. (2002) Regression2 Based Inequality Decomposition: Pitfalls and a Solution Procedure. WID2ER Discussion Paper.

Submit or recommend next manuscript to SCIRP and we will provide best service for you:

Accepting pre-submission inquiries through Email, Facebook, LinkedIn, Twitter, etc. A wide selection of journals (inclusive of 9 subjects, more than 200 journals)

Providing 24-hour high-quality service

User-friendly online submission system

Fair and swift peer-review system

Efficient typesetting and proofreading procedure

Display of the result of downloads and visits, as well as the number of cited articles Maximum dissemination of your research work

Submit your manuscript at: http://papersubmission.scirp.org/

Or contact me@scirp.org 